\title{
0 laboratório clínico na investigação dos distúrbios da hemoglobina
}

\author{
The clinical laboratory in the investigation of hemoglobin disorders
}

Lais Pinto de Almeida'; Annelise Corrêa Wengerkievicz²; Nilceia Maria Viviani³;

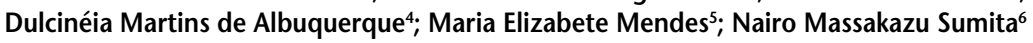

\author{
unitermos \\ Hemoglobina \\ Hemoglobina variante \\ Hemoglobinopatia \\ Talassemia \\ Métodos laboratoriais \\ Patologia clínica
}

\section{resumo}

As alterações na síntese da hemoglobina resultam em um grupo de distúrbios hereditários, os quais podem ser classificados como hemoglobina variante, se a alteração tiver origem em uma mutação no gene da hemoglobina, produzindo cadeias anormais, ou como talassemias, se a estrutura é normal, porém a síntese ocorre em quantidade alterada. Este trabalho tem como objetivo descrever a condução do diagnóstico laboratorial de quatro casos de distúrbios da hemoglobina, a fim de ilustrar o papel do laboratório e discutir o papel do patologista clínico como elemento de elo entre a clínica e o laboratório no processo de elucidação diagnóstica. abstract

Defective synthesis of hemoglobin gives rise to a group of hereditary disorders. If the defect arises from a genetic mutation producing abnormal protein chains, the condition is classified as hemoglobin variant. Whereas, if the structure is normal but the synthesis is reduced, they are denominated as thalassaemia. This article aims to describe the laboratory diagnostic approach in four cases of hemoglobin disorders in order to illustrate the role of laboratories and discuss the role of clinical pathologists as a link between physicians and laboratories in diagnostic clarification. 


\section{Introdução}

A hemoglobina $(\mathrm{Hb})$ é uma molécula esferoidal cuja principal função nas hemácias é o transporte de oxigênio $\left(\mathrm{O}_{2}\right)$ para os tecidos ${ }^{(14)}$. Sua estrutura é composta de quatro subunidades formadas de dois pares de cadeias polipeptídicas idênticas, chamadas globinas, cada uma ligada a um grupo heme. Usualmente, as cadeias polipeptídicas consistem em um par de cadeias $\alpha$ ou $\alpha$-like e um par de cadeias não- $\alpha$, que pode ser $\beta, \gamma, \delta$ ou $\varepsilon^{(4)}$. O grupo heme, por sua vez, é formado de ferro e porfirina e é responsável pela captação e pela liberação de $\mathrm{O}_{2}$ nos tecidos ${ }^{(14)}$.

O perfil da hemoglobina do adulto normal contém em torno de $97 \%$ de $\mathrm{HbA}$ (duas cadeias $\alpha$-globina e duas cadeias $\beta$-globina, representadas por $\left.\alpha_{2} \beta_{2}\right), 2 \%$ de $\mathrm{HbA}_{2}\left(\alpha_{22}\right)$ e $1 \%$ de $\mathrm{Hb}$ fetal $\left(\mathrm{HbF}\right.$, cuja representação é $\left.\alpha_{2} \gamma_{2}\right)$, que é a $\mathrm{Hb}$ predominante na vida intrauterina. Essa distribuição resulta do padrão de expressão dos genes da $\alpha$-globina no cromossomo 16 e da $\beta, \gamma$ ou $\delta$-globina no cromossomo $11^{(14)}$. Outras $\mathrm{Hb}$ normais do período embrionário são Portland $\left(\zeta_{2} \gamma_{2}\right)$, Gower-1 $\left(\zeta_{2} \varepsilon_{2}\right)$ e Gower-2 $\left(\alpha_{2} \varepsilon_{2}\right)$, que não são encontradas após o nascimento ${ }^{(4)}$.

Alterações na síntese da $\mathrm{Hb}$ resultam em um grupo heterogêneo de distúrbios hereditários, classificados de acordo com o defeito resultante. Se a alteração tem origem em uma mutação no gene da $\mathrm{Hb}$, produzindo cadeias polipeptídicas anormais, a condição é chamada de $\mathrm{Hb}$ variante $(\mathrm{HbV})$ ou hemoglobinopatia; porém, se a estrutura é normal, mas a síntese das cadeias ocorre em quantidade alterada, é classificada como talassemia ${ }^{(6)}$.

As síndromes clínicas associadas às talassemias resultam da combinação de produção inadequada de um par de cadeias globínicas (dando origem a anemia, hipocromia e microcitose) e do acúmulo de outro par (que leva a eritropoese ineficiente e hemólise) ${ }^{(12)}$. Os defeitos genéticos subjacentes são, na maior parte das vezes, mutações pontuais, mas também são descritas deleções de um ou mais nucleotídeos, inversões ou rearranjos de sequências de $D N A^{(5)}$, que podem ocorrer em um dos genes da cadeia $\alpha, \beta, \gamma$ ou $\delta$. Essa diversidade de defeitos genéticos associados às talassemias resulta na heterogeneidade do quadro clínico, que pode variar desde microcitose assintomática até incompatibilidade com a vida e morte intrauterina ${ }^{(12)}$.

Previamente ao desenvolvimento das técnicas de biologia molecular, as talassemias eram classificadas de acordo com sua severidade clínica. Assim, a talassemia major apresentava-se com anemia severa e manifestações clínicas; na talassemia intermédia, as manifestações não eram severas a ponto de necessitar de transfusões frequentes; a talassemia minor era observada em pais de crianças com talassemia major que apresentavam anemia discreta e microcitose; a talassemia mínima era encontrada em indivíduos carreadores obrigatórios do gene, porém sem nenhuma anormalidade na série vermelha. Hoje, a classificação é realizada segundo a cadeia cuja síntese está comprometida ${ }^{(10)}$.

Assim como as talassemias, as manifestações clínicas resultantes das $\mathrm{HbV}$ são muito variáveis. Muitas vezes, a $\mathrm{Hb}$ resultante conserva função normal, sendo clinicamente silenciosa. Algumas podem formar polímeros ou cristais, que provocam hemólise; outras são instáveis, produzindo hemólise crônica ou intermitente; outras ainda possuem afinidade alterada pelo $\mathrm{O}_{2}^{(10)}$.

As $\mathrm{HbV}$ representam a desordem genética mais comum; acredita-se que $4,5 \%$ da população mundial seja portadora de um gene com alguma anomalia ${ }^{(11)}$. Uma infinidade de mutações associadas às $\mathrm{HbV}$ já foi descrita, a maioria tendo origem na substituição de um aminoácido, com descrições também de deleções, inserções e fusão de duas cadeias polipeptídicas diferentes ${ }^{(1-3,8,10)}$. A distribuição e a alta frequência em algumas comunidades refletem o fato de conferirem uma vantagem seletiva em regiões endêmicas para $P$. falciparum, uma vez que as hemácias se tornam ambientes inóspitos para esse parasita.

As talassemias e a HbV já foram extensivamente estudadas quanto aos aspectos bioquímicos, hematológicos e moleculares. No entanto, continuam representando um desafio diagnóstico, especialmente em comunidades multiétnicas. Sua detecção precoce possibilita o aconselhamento genético de casais com alto risco de consequências hematológicas graves, bem como o acompanhamento rigoroso das gestações de risco ${ }^{(16)}$.

A partir da década de 1980, uma grande quantidade de ferramentas diagnósticas passou a ser disponibilizada pelo laboratório, observando-se a modernização dos equipamentos e a simplificação dos procedimentos ${ }^{(11)}$.

Este trabalho tem como objetivo descrever o diagnóstico laboratorial de quatro casos clínicos observados no Serviço de Bioquímica Clínica da Divisão de Laboratório Central do Hospital das Clínicas da Faculdade de Medicina da Universidade de São Paulo (DLC/HC-FMUSP), com a finalidade de ilustrar a importância do laboratório clínico no diagnóstico das HbV e talassemias e discutir o papel do patologista clínico como elemento de elo entre a clínica e o laboratório no processo de elucidação diagnóstica. 


\section{Caso 1}

Paciente do sexo feminino, 25 anos de idade, branca, no curso da $33^{\text {a }}$ semana de gestação, foi admitida no hospital em razão de sangramento vaginal de pequena intensidade. O exame ultrassonográfico demonstrou quadro de placenta prévia centro-total, sem sinais de acretismo, além da presença de mioma uterino anterior fazendo saliência na cavidade amniótica. O hemograma revelou quadro de anemia normocítica e normocrômica, com red cell distribution width (RDW) ou índice de anisocitose normal (Tabela).

Tabela Parâmetros do eritrograma e exames adicionais de triagem dos pacientes descritos

\begin{tabular}{|c|c|c|c|c|c|c|c|c|}
\hline & Valor de & erência & & & & & Caso 4 & \\
\hline & $F$ & M & Caso 1 & Caso 2 & Caso 3 & Paciente & $\begin{array}{l}\text { Mãe da } \\
\text { paciente }\end{array}$ & $\begin{array}{l}\text { Filha da } \\
\text { paciente }\end{array}$ \\
\hline $\begin{array}{l}\text { Eritrócitos } \\
\text { (milhões } / \mathrm{mm}^{3} \text { ) }\end{array}$ & $4-5,4$ & $4,4-5,9$ & 3,96 & 3,3 & 5,03 & 5,92 & 4,45 & 5,38 \\
\hline $\begin{array}{l}\text { Hemoglobina } \\
\text { (g/dl) }\end{array}$ & $12-16$ & $13-18$ & 10,8 & 9,9 & 11,1 & 11,7 & 9,7 & 10,6 \\
\hline Hematócrito (\%) & $35-47$ & $40-52$ & 34,6 & 33,7 & 35,6 & 35,9 & 29 & 31,3 \\
\hline $\operatorname{VCM}\left(\mu^{3}\right)$ & $80-100$ & 87,4 & 102,1 & 70,8 & 60,6 & 65,2 & 58,2 & \\
\hline HCM (pg) & $27-30$ & 27,3 & 30 & 22,1 & 19,8 & 21,8 & 19,7 & \\
\hline CHCM (g/dl) & $32-37$ & 31,2 & 29,4 & 31,2 & 32,6 & 33,4 & 33,9 & \\
\hline RDW (\%) & $9,5-16$ & 13,6 & 15,5 & 16,3 & 19 & 16,9 & 23,3 & \\
\hline $\begin{array}{l}\text { Contagem de } \\
\text { reticulócitos (\%) }\end{array}$ & $0,5-2,7$ & 1,74 & 10,85 & 0,8 & 2,48 & NR & 2,57 & \\
\hline Ferritina $(\mu \mathrm{g} / \mathrm{l})$ & $10-140$ & 108 & 11 & 45 & 89 & 33 & 38 & \\
\hline $\begin{array}{l}\text { Transferrina } \\
\text { (mg/dl) }\end{array}$ & $203-360$ & 280 & 440 & 230 & NR & NR & NR & \\
\hline Ferro ( $\mu \mathrm{g} / \mathrm{dl})$ & $50-150$ & 35 & 119 & 22 & 111 & 57 & 128 & \\
\hline $\begin{array}{l}\text { Capacidade total } \\
\text { de ligação Ferro } \\
(\mu \mathrm{g} / \mathrm{dl})\end{array}$ & $250-380$ & 284 & 507 & 323 & NR & NR & NR & \\
\hline $\begin{array}{l}\text { Saturação do } \\
\text { ferro }\end{array}$ & $20-40$ & 12,32 & 23,47 & 7 & NR & NR & NR & \\
\hline
\end{tabular}

F: sexo feminino; M: sexo masculino; VCM: volume corpuscular médio; HCM: hemoglobina corpuscular média; CHCM: concentração hemoglobínica corpuscular média; RDW: red cell distribution width; NR: não realizado.

A investigação para coagulopatias e eventual processo infeccioso resultou negativa. Foi iniciada reposição de ferro, porém os níveis de Hb se mantiveram entre 9,9 e 10,2 g/dl. Ao ampliar a investigação, evidenciaram-se níveis de transferrina, capacidade total de ligação do ferro e ferritina normais, a despeito do ferro sérico e da saturação da transferrina discretamente reduzidos (Tabela). A eletroforese de $\mathrm{Hb}$ em meio alcalino demonstrou presença de uma fração de $\mathrm{HbV}$ em posição anterior a $\mathrm{HbA}$ (Figura 1A) e sobreposta a $\mathrm{HbA}$ em meio ácido (Figura 1B), com tempo de retenção de 1,60 minutos, sugestivo de $\mathrm{HbJ}$ (Figura 1C). Foi sugerido ao médico assistente que a $\mathrm{Hb}$ em questão poderia tratar-se de HbJ de Pierre-Bénite, sendo indicado o estudo molecular para confirmação do diagnóstico.

\section{Caso 2}

Paciente do sexo feminino, 17 anos de idade, admitida na enfermaria com queixa de astenia e dispneia a moderados esforços, referia estar em uso de fenazopiridina há sete dias devido a quadro de disúria, sem febre. O hemograma, no momento da admissão, evidenciou $\mathrm{Hb}=4,7 \mathrm{mg} / \mathrm{dl}$ e leucocitose $\left(28.000 / \mathrm{mm}^{3}\right)$ com contagem diferencial de neutrófilos no intervalo de referência, porém com presença de esquizócitos e aumento de reticulócitos. O nível de bilirrubina indireta também se encontrava elevado. A paciente apresentou evolução clínica favorável, porém, em virtude da transfusão, a investigação laboratorial da anemia hemolítica necessitou ser adiada. 


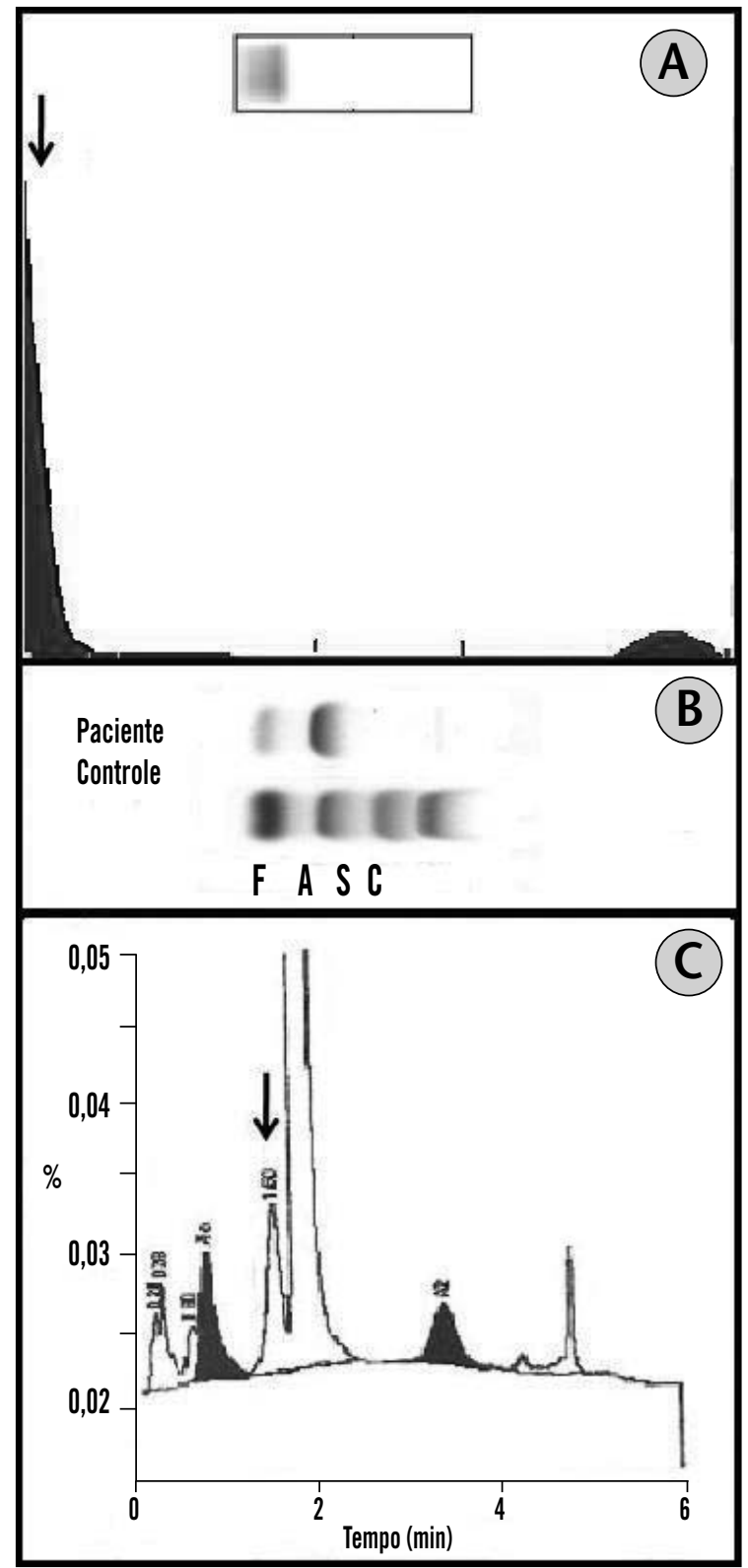

Figura 1 - (A) Eletroforese de Hb em meio alcalino, acompanhada de leitura densitométrica: $\mathrm{HbV}$ posicionando-se anteriormente à $\mathrm{HbA}$, em posição de $\mathrm{Hb}$ "rápida" (seta); (B) eletroforese de $\mathrm{Hb}$ em meio ácido mostra a fração de $\mathrm{HbV}$ sobreposta à $\mathrm{HbA}$; (C) HPLC indicando uma HbV com tempo de retenção de 1,60 minutos (seta)

$H b$ : hemoglobina; HPLC: cromatografia líquida de alta eficiência.

Dois meses após a alta hospitalar, desenvolveu quadro de gravidez, tendo a gestação evoluída sem intercorrências. Após o parto, foi realizada investigação hematológica cujos resultados estão descritos na Tabela. Detectou-se elevação da atividade da desidrogenase láctica e do nível de bilirrubinas às custas da bilirrubina indireta. A pesquisa de anticorpos irregulares e o teste de antiglobulina direto resultaram negativos. Em virtude da utilização da fenazopiridina na ocasião do primeiro episódio hemolítico, foi realizada a medida da atividade das enzimas glicose-6fosfato-desidrogenase e piruvato-quinase, que também resultou normal. A eletroforese de $\mathrm{Hb}$ evidenciou pico em heterozigose na posição de hemoglobina falciforme mutante (HbS) em meio alcalino (Figura 2A) e sobre a $\mathrm{HbA}$ em meio ácido (Figura 2B). O método de cromatografia líquida de alta eficiência (HPLC) caracterizou uma $\mathrm{Hb}$ com tempo de retenção semelhante ao da $\mathrm{HbA}_{2}$ (Figura 2C). $\mathrm{O}$ teste de desnaturação com calor e precipitação com isopropanol foi positivo, sugerindo tratar-se de uma $\mathrm{Hb}$ instável. Nesse contexto, foi sugerido ao médico assistente encaminhar a paciente a um serviço que pudesse elucidar o caso por meio de estudo molecular.

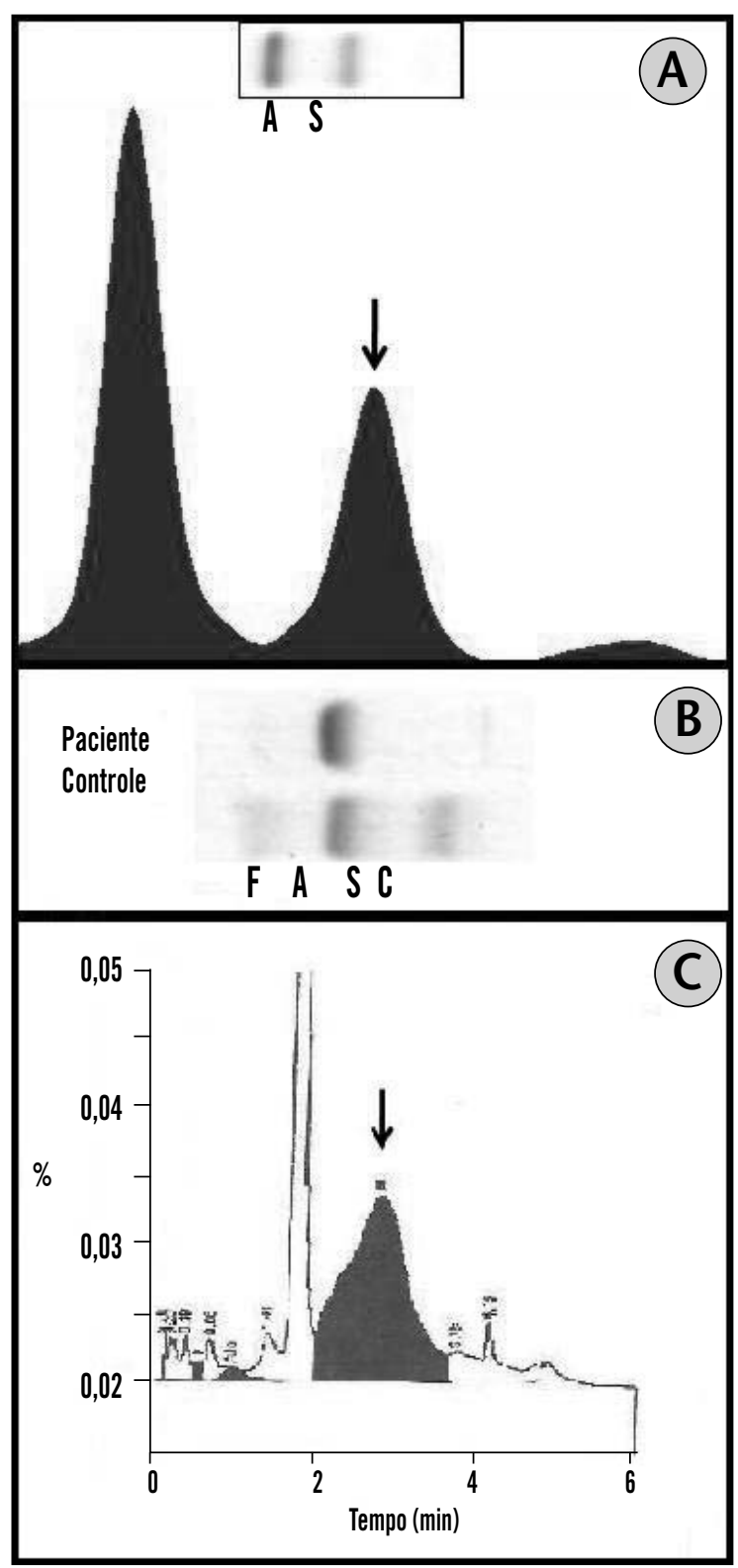

Figura 2 - (A) Eletroforese de $\mathrm{Hb}$ em meio alcalino, acompanhada de leitura densitométrica: presença de fração de $\mathrm{Hb}$ em posição de $\mathrm{HbS}$ (seta); (B) eletroforese de $\mathrm{Hb}$ em meio ácido mostra a fração de $\mathrm{HbV}$ sobreposta à $\mathrm{HbA}$; (C) HPLC indicando uma $\mathrm{HbV}$ com tempo de retenção semelhante ao da $\mathrm{HbA}_{2}$ (seta)

$H b$ : hemoglobina; HPLC: cromatografia líquida de alta eficiência. 


\section{Caso 3}

Paciente do sexo masculino, 11 anos de idade, admitido com quadro febril; quadro de anemia (Tabela) diagnosticado durante a internação. Optou-se pela realização de eletroforese de $\mathrm{Hb}$, que revelou a presença de $\mathrm{Hb}$ anormal migrando entre as posições das $\mathrm{HbA}$ e $\mathrm{HbS}$ em meio alcalino (Figura 3A) e na posição da HbA em meio ácido (Figura 3B), sugerindo presença de HbV. O método HPLC caracterizou tempo de retenção semelhante ao da $\mathrm{HbA}_{2}$ em $52,4 \%$ da $\mathrm{Hb}$ (Figura 3C). Para o diagnóstico definitivo, aplicou-se técnica molecular de sequenciamento, que detectou a troca de um aminoácido histidina (His) por arginina (Arg) no códon 6, em heterozigose, compatível com Hb Deer Lodge (Figura 3D).

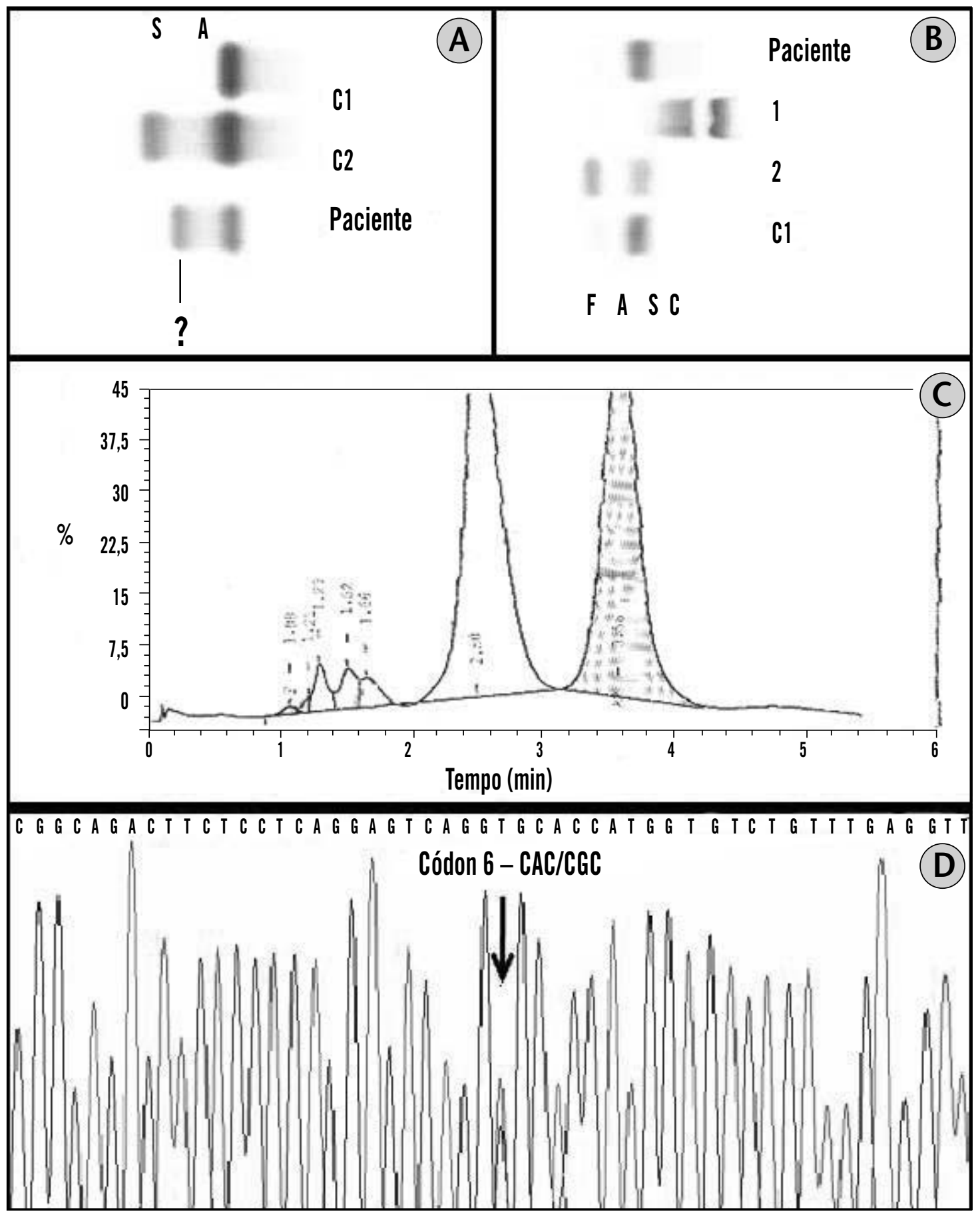

Figura 3 - (A) Eletroforese alcalina da amostra do paciente comparada com controles comerciais de HbA (C1) e HbAS (C2). Observa-se que a Hb desconhecida (?) migra em posição entre as $\mathrm{HbA}$ e $\mathrm{HbAS}$; (B) análise eletroforética de $\mathrm{Hb}$ em meio ácido da amostra do paciente comparada com as amostras com HbSC (1) e HbA e com o aumento de $\mathrm{HbF}$ (2) e controle comercial de $\mathrm{HbA}$ (C1). Observa-se que nesse $\mathrm{pH}$, a Hb desconhecida migra na posição da HbA; (C) HPLC: aumento no tempo de retenção entre 3 e 4 minutos, em posição semelhante à $\mathrm{HbA}_{2}$; $(\mathbf{D})$ representação gráfica da técnica de sequenciamento: Hb Deer Lodge, troca de um aminoácido histidina por arginina no códon 6 , em heterozigose Hb: hemoglobina; pH: concentração de íon hidrogênio; HPLC: cromatografia líquida de alta eficiência. 


\section{Caso 4}

Puérpera, 19 anos de idade, foi internada para investigação de anemia sintomática. O hemograma revelou hemácias microcíticas e hipocrômicas, com presença de ovalócitos e significativa pecilocitose. A eletroforese de $\mathrm{Hb}$ em meio alcalino detectou diminuição relativa de $\mathrm{HbA}(89,3 \%)$, elevação da $\mathrm{HbF}(4,2 \%)$ e $\mathrm{HbA}_{2}(6,5 \%)$ (Figura 4A). As hemácias apresentavam resistência osmótica a $\mathrm{NaCl} 0,36 \%$.

A mãe da paciente, com 42 anos de idade, apresentava quadro de anemia com índices hematimétricos semelhantes (Tabela). A filha da paciente, com 10 meses de idade, apresentava anemia microcítica e hipocrômica, pecilocitose e presença de esquizócitos, dacriócitos e policromasia ao hemograma (Tabela). O padrão eletroforético das $\mathrm{Hb}$ foi compatível com um quadro de heterozigose para talassemia. A análise molecular revelou substituição do primeiro nucleotídeo, originando um stop codon (GAG $\rightarrow$ TAG) no sexto códon da cadeia $\beta$-globínica, levando à síntese reduzida da cadeia $\beta$ (Figura 4B).

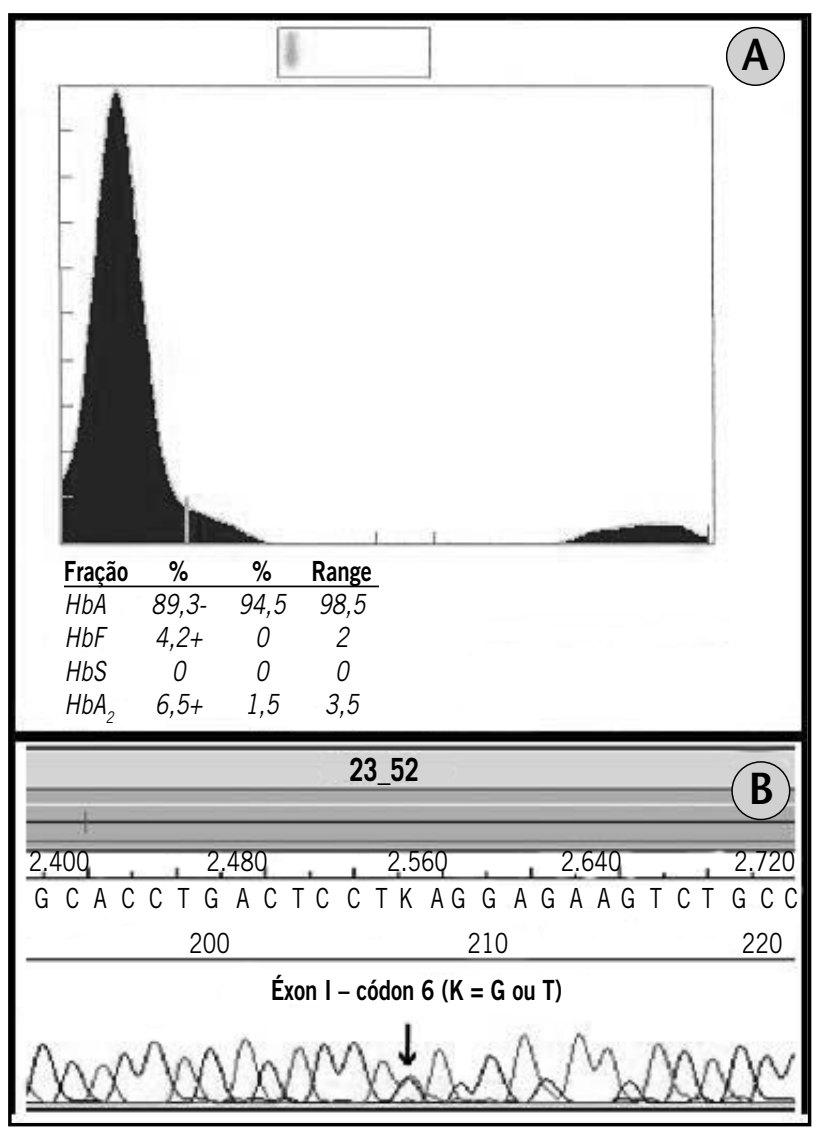

Figura 4 - (A) Eletroforese de $\mathrm{Hb}$ em meio alcalino, acompanhada de leitura densito-

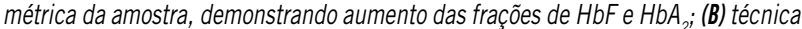
molecular de sequenciamento evidenciando mutação no códon $6(G \rightarrow T)$ (seta) $\mathrm{Hb}$ : hemoglobina.

\section{Discussão}

Em 1975, o Comitê Internacional de Padronização em Hematologia (ICSH) lançou um painel de recomendações visando ao diagnóstico e à investigação laboratorial das $\mathrm{HbV}$ e talassemias. A triagem inicial recomendada inclui hemograma, dosagem de ferro e ferritina, eletroforese de $\mathrm{Hb}$ em meio alcalino, teste de solubilidade, teste de falcização e quantificação de $\mathrm{HbA}_{2}$ e $\mathrm{HbF}$. Na detecção de alguma anormalidade, aplicam-se técnicas de maior resolução: eletroforese de globinas (o método de HPLC), eletroforese por focalização isoelétrica (IEF) e, por fim, a análise molecular por reação em cadeia da polimerase (PCR) e sequenciamento genético(6).

A triagem hematológica inicial é fundamental, sendo que é recomendada a utilização de um contador hematológico moderno com medidas acuradas de volume corpuscular médio (VCM), contagem de eritrócitos ( $R B C$ ), hemoglobina corpuscular média (HCM) e concentração hemoglobínica corpuscular média (CHCM) ${ }^{(13)}$. A maioria dos programas de triagem populacional utiliza o valor de VCM $<80 \mathrm{fL}$ e uma $\mathrm{HCM}<27 \mathrm{pg}$ como pontos de corte para a investigação adicional das talassemias( ${ }^{(7)}$. Esses dados, em um contexto de RBC normal/alto, são altamente sugestivos para o diagnóstico de talassemia, como observado no quarto caso. O RDW normal associado ao exame do esfregaço auxilia na triagem inicial da talassemia, além de permitir identificar outras condições, como o portador de HbS, por meio da observação de hemácias falcizadas. A presença de $\mathrm{Hb}$ instáveis, que levam à formação de corpúsculos de Heinz, ou, como no segundo caso, a presença de esquizócitos sugere hemólise intravascular ${ }^{(9)}$.

Uma vez aventada a suspeita de talassemia ou $\mathrm{HbV}$ pelo hemograma, outros exames hematológicos devem ser realizados para a confirmação e a caracterização adicional. Inicialmente, é indicada a dosagem de ferritina; se for necessário, indicam-se também as dosagens de ferro sérico, a capacidade total de ligação do ferro e a saturação da transferrina para afastar a existência de anemias carenciais, que são consideradas diagnósticos diferenciais ${ }^{(16)}$.

Excluídas as anemias carenciais, a investigação requer a realização simultânea de testes laboratoriais que avaliem o perfil das $\mathrm{Hb}$. Eles incluem eletroforese de $\mathrm{Hb}$ e estudo do perfil pelo método de HPLC.

A eletroforese de $\mathrm{Hb}$ em meio alcalino é um método rápido e reprodutível, que separa hemoglobinas $S, F, C, A$ e $A_{2^{\prime}}$ possibilitando a quantificação das bandas maiores. Devido 
à sobreposição de algumas $\mathrm{Hb}$ no pH de 8,6, utiliza-se para discriminação a eletroforese em meio ácido $(\mathrm{pH}=6-6,2)$, que separa a $\mathrm{HbS}$ de $\mathrm{D}$ e $\mathrm{G}$ e a $\mathrm{HbC}$ da E e O (sobrepostas em meio alcalino) ${ }^{(13)}$. A eletroforese é útil na identificação da presença de traços talassêmicos, caracterizados pelo aumento de $\mathrm{HbA}_{2}$, HbF e HbV. No entanto, $\mathrm{Hb}$ instáveis que sofrem rápida desnaturação ou posicionam-se sobre a fração da $\mathrm{HbA}$ podem não ser detectadas por esse método. Essas considerações justificam o fato de uma eletroforese de $\mathrm{Hb}$ normal não excluir diagnósticos quando de alta probabilidade pré-teste, por exemplo, anemia hemolítica inexplicada na presença de corpúsculos de Heinz e policromasia no sangue periférico(17).

O método de HPLC tornou-se, nos últimos 20 anos, uma ferramenta indispensável na avaliação das hemoglobinopatias e na separação e na determinação de porcentagens de $\mathrm{HbA}, \mathrm{HbA}_{2}$ e $\mathrm{HbF}^{(13)}$. A metodologia apresenta melhor grau de resolução e confiabilidade para quantificação da $\mathrm{HbA}_{2}$ quando em comparação com os métodos eletroforéti$\cos ^{(13)}$. Permite separar diferentes tipos de $\mathrm{Hb}$ com base nos tempos de interação que elas apresentam com uma coluna de troca iônica. Além da informação numérica, fornece ainda a apresentação gráfica dos dados, permitindo uma análise mais ampla e confiável do que as conclusões da exploração de uma representação numérica. No entanto, exige experiência e treinamento dos profissionais do laboratório, uma vez que há um vasto banco de dados para caracterização das HbV, com base nos diferentes tempos de retenção, pelo método de HPLC. Como consequência, a grande quantidade de interpretações possíveis aumenta consideravelmente ${ }^{(15)}$.

Sempre que existe suspeita de uma $\mathrm{Hb}$ anômala, outros testes podem ser indicados, como, por exemplo, a pesquisa de inclusões nas hemácias, os testes de instabilidade e solubilidade de $\mathrm{Hb}$ e os testes de desnaturação(11). Alguns desses testes são trabalhosos e requerem habilidade técnica e experiência para a correta interpretação dos resultados.

Outros testes especiais são descritos, particularmente na investigação de variantes mais raras, como teste de afinidade do oxigênio, detecção da meta-hemoglobina e espectrometria de massas para caracterização das hemoglobinas $^{(18)}$. Apesar de úteis, eles não dispensam a caracterização molecular, exame que permanece como o de escolha para o diagnóstico definitivo. No estudo molecular, é necessário ressaltar que deve ser construída uma hipótese do provável defeito, uma vez que é preciso definir qual dos genes de cadeias globínicas ( $\alpha$ ou $\beta$ ) será estudado pela PCR, bem como o tipo de mutação esperado (deleções ou mutações pontuais). As $\alpha$-talassemias são geralmente causadas por deleções, e as $\beta$-talassemias e as $\mathrm{HbV}$ resultam de mutações pontuais. A pesquisa de mutações pontuais requer o emprego de técnicas como gap-PCR, estudo de fragmentos de restrição e ainda sequenciamento de DNA, visto que o PCR comum pode não detectar essas alterações. A importância do diagnóstico molecular está no fato de permitir, além do diagnóstico definitivo, a confirmação do tipo de hemoglobinopatia e o posterior aconselhamento genético(16).

Apesar do impacto gerado pelo diagnóstico molecular sobre a compreensão e a detecção dessas condições, a pesquisa de mutações não deve ser considerada o primeiro teste a ser realizado na suspeita clínica. Acredita-se que a melhor estratégia seria a associação dos achados do hemograma aos dos testes especiais em hematologia e, finalmente, a pesquisa das alterações moleculares, quer sejam mutações primárias ou interações gene-gene influenciando o fenótipo. Apesar de termos mencionado um número pequeno de $\mathrm{HbV}$, são descritas mais de mil mutações associadas a hemoglobinopatias ${ }^{(16)}$.

\section{Conclusão}

A significativa prevalência de talassemias e HbV, associada à diversidade de alterações genéticas que originam essas condições, determina o desafio diagnóstico na prática clínica. A investigação por meio das técnicas de biologia molecular, apesar de definitiva, torna-se economicamente inviável, com risco de obtenção de resultados inconclusivos, caso não seja precedida de uma avaliação laboratorial ampla e um direcionamento diagnóstico.

Destaca-se o importante papel do patologista clínico em auxiliar o médico a aplicar algoritmos diagnósticos, visando ao uso racional do laboratório, bem como apresentar os métodos disponíveis no laboratório, com o objetivo de discutir as vantagens e as limitações de cada metodologia. A interpretação adequada de um resultado laboratorial nas doenças que afetam a $\mathrm{Hb}$ exige profissionais da área laboratorial com elevado nível de treinamento e experiência nesse tema. A abordagem clínico-laboratorial, aliada ao estudo familiar, permitirá o direcionamento diagnóstico de forma eficiente, evitando etapas desnecessárias no processo diagnóstico. 


\section{Referências}

1. AYALA, S.; COLOMER, D. et al. Haemoglobin Lleida: a new alpha 2-globin variant (12 bp deletion) with mild thalassaemic phenotype. Br J Haematol, v. 94, n. 4, p. 639-44, 1996.

2. Beard, M. E.; Potter, H. C. et al. Haemoglobin PierreBenite $-a$ high affinity variant associated with relative polycythaemia. Clin Lab Haematol, v. 23, n. 6, p. 407-9, 2001.

3. Bissé, E.; Schaeffer, C. et al. Haemoglobin Noah Mehmet Oeztuerk (alpha(2) delta(2)143 (h21)his->tyr. a novel delta-chain variant in the 2,3-dpg binding site. J Chromatogr B Analyt Technol Biomed Life Sci, v. 871, n. 1, p. 55-9, 2008.

4. Burtis, C. A.; Ashwood, E. R. et al. Tietz textbook of clinical chemistry and molecular diagnostics. Elsevier Saunders, 2006.

5. CLARK, B. E.; THEIN, S. L. Molecular diagnosis of haemoglobin disorders. Clin Lab Haematology, v. 26, p. 159-76, 2004.

6. CLARKE, G. M.; HIGGINS, T. N. Laboratory investigation of hemoglobinopathies and thalassemias: review and update. Clin Chem, v. 46, n. 8, p. 1284-90, 2000.

7. Colah, R. B.; Surve, R. et al. HPLC studies in hemoglobinopathies. Indian J Pediatr, v. 74, p. 657-62, 2006.

8. De Rosa, M. C.; Carelli Alinovi, C. et al. Hb Santa Clara (beta 97his->asn), a human haemoglobin variant: functional characterization and structure modelling. Biochim Biophys Acta, v. 1774, n. 10, p. 1299-306, 2007.
9. ENGLAND, J. M.; FRASE, P. M. Differentiation of iron deficiency from thalassaemia trait by routine bloodcount. Lancet, v. 1, p. 449-52, 1973.

10. Greer, J. P.; Foerster, J. et al. Wintrobe's clinical hematology. Lippincott Williams \& Wilkins, 2008.

11. KOHNE, E.; KLEIHAUER, E. Hemoglobinopathies: a longitudinal study over four decades. Dtsch Arztebl Int, v. 107, n. 5, p. 65-71, 2010.

12. Lewis, S. M.; Bain, B. J. et al. Hematologia prática de Dacie e Lewis. Artmed, 2006.

13. MCPHERSON, R. A.; PINCUS, M. R. Henry's clinical diagnosis and management by laboratory methods. Elsevier Saunders, 2007.

14. SCHECHTER, A. N. Hemoglobin research and the origins of molecular medicine. Blood, v. 112, n. 10, p. 3927-38, 2008.

15. Storti-Melo, L. M.; Mangonaro, P. H. et al. Threedimensional visualization of human hemoglobin phenotypes with HPLC. Genet Mol Res, v. 8, n. 1, p. 354-63, 2009.

16. TRENT, R. J. A. Diagnosis of the haemoglobinopathies. Clin Biochem Rev, v. 27, n. 1, p. 27-38, 2006.

17. Yates, A. M.; Mortier, N. A. et al. The diagnostic dilemma of congenital unstable hemoglobinopathies. Pediatr Blood Cancer, v. 55, p. 1393-5, 2010.

18. Zanella-Cleon, I.; Joly, P. et al. Phenotype determination of hemoglobinopathies by mass spectrometry. Clin Biochem, v. 42, p. 1807-17, 2009. 